\title{
Spatial mixing of mitochondrial lineages and greater genetic diversity in some invasive populations of the American mink (Neovison vison) compared to native populations
}

Article

Accepted Version

García, K., Melero, Y., Palazón, S., Gosálbez, J. and Castresana, J. (2017) Spatial mixing of mitochondrial lineages and greater genetic diversity in some invasive populations of the American mink (Neovison vison) compared to native populations. Biological Invasions, 19 (9). pp. 2663-2673. ISSN 1387-3547 doi: https://doi.org/10.1007/s10530-017-1475-4 Available at https://centaur.reading.ac.uk/83099/

It is advisable to refer to the publisher's version if you intend to cite from the work. See Guidance on citing.

To link to this article DOI: http://dx.doi.org/10.1007/s10530-017-1475-4

Publisher: Springer

All outputs in CentAUR are protected by Intellectual Property Rights law, including copyright law. Copyright and IPR is retained by the creators or other copyright holders. Terms and conditions for use of this material are defined in the End User Agreement. 


\section{www.reading.ac.uk/centaur}

\section{CentAUR}

Central Archive at the University of Reading

Reading's research outputs online 
1 Spatial mixing of mitochondrial lineages and greater genetic diversity in some invasive populations

2 of the American mink (Neovison vison) compared to native populations

3

4 Karla García ${ }^{1 *}$, Yolanda Melero ${ }^{2}$, Santiago Palazón ${ }^{1,3}$, Joaquim Gosálbez ${ }^{1}$ and Jose Castresana ${ }^{4}$

5

$6{ }^{1}$ Department of Evolutionary Biology, Ecology and Environmental Sciences, University of Barcelona,

708028 Barcelona, Spain. *Correspondence: karla.garcia.cl@gmail.com

8

$9 \quad{ }^{2}$ CREAF, 08193 Cerdanyola del Vallès, Spain.

10

$11{ }^{3}$ Fauna and Flora Service, Department of Territory and Sustainability, Government of Catalonia, 08017

12 Barcelona, Spain.

13

$14{ }^{4}$ Institute of Evolutionary Biology (CSIC-Universitat Pompeu Fabra), 08003 Barcelona, Spain.

15

16 


\section{Abstract}

The genetic characteristics of introduced populations have a relevant impact on their ability to

20 establish and spread. The American mink (Neovison vison), native to North America, is an important

21 invasive species in the Iberian Peninsula. Here, we used mitochondrial DNA sequences data to investigate

22 the genetic diversity and phylogeographic structure of invasive vs. native populations of this species. We

23 also evaluated whether genetic diversity in invasive populations could be explained by the genetic

24 characteristics of the native sources from which they derived. Phylogenetic analysis revealed two major

25 lineages in the native range, which indicated a clear separation between western and eastern populations.

26 On the contrary, we found no evidence of genetic structure in the invasive range. This was probably the

27 result of the diverse origins of the released specimens and the rapid expansion and encounters of the

28 introduced populations. We detected spatial mixing of both North American lineages in several sampling

29 localities of the north central area of the Iberian Peninsula, giving rise to high levels of genetic diversity

30 in some areas compared to North American populations. This could potentially lead to higher fitness of

31 these individuals and thus increase the population viability and invasiveness of this species. These results

32 point to the need to better study the populations in which lineages mix and, if necessary, intensify control

33 efforts in them.

34

35 Keywords: American mink, mitochondrial genes, genetic diversity, native range, Iberian Peninsula. 


\section{Introduction}

Identifying the biological attributes of successful invaders is among the most pressing questions yet to be answered (Sol et al. 2012). Although there is evidence that species differ in their invasion potential, controversy exits about the characteristics that differentiate successful and unsuccessful invaders (Blackburn et al. 2009). Other studies of introduced species show that genetics might play an integral role in the success of an invasion, and they suggest that this role is determined by the quality of the genetic variation introduced, rather than the total quantity of genetic variation (see Dlugosch et al. 2015). The genetic diversity of founding populations, along with potential increase in genetic diversity from subsequent introductions, may be important to the successful establishment and spread of introduced species (Suarez and Tsutsui 2008; Sol et al. 2012). Nevertheless, there is no consensus on whether invaders stemming from multiple native origins are more successful than those from single populations, or whether demographic bottlenecks may limit the invasion success of a species (Edelaar et al. 2015; Estoup 2016).

Overall, introduced populations lose genetic variation relative to their source populations (Dlugosch and Parker 2008). However, numerous introduction events and a greater number of source populations may buffer against such genetic losses (Kolbe et al. 2004; Dlugosch and Parker 2008; Uller and Leimu 2011). In fact, in some cases successful invaders show large increases in genetic diversity in the introduced range, apparently caused by mixing of populations from different source regions (Genton et al. 2005; Novak and Mack 1993). Therefore, it is crucial to obtain information on the phylogeographic structure and genetic diversity throughout the native and introduced ranges to understand the factors affecting genetic diversity during invasion (e.g. multiple introduction events or admixture levels among populations) and the interaction between genetic diversity and invasive potential (Edelaar et al. 2015).

The American mink (Neovison vison) is a successful invader with a native range restricted to North America and with invasive populations distributed across Europe, Asia and South America (Bonesi and Palazón 2007; Dunstone 1993). In Europe, this species was introduced for commercial fur farming during the $20^{\text {th }}$ century. Populations established by escaped individuals are now naturalised in fresh water and coastal ecosystems (Bonesi and Palazón 2007), with detrimental consequences for the abundance of many native species of prey and competitors of conservation importance (Bonesi et al. 2004; Harrington et al. 2009; Macdonald and Harrington 2003; Melero et al. 2012a), including critically endangered species such as the European mink (Mustela lutreola) (Maran et al. 2016) and the Pyrenean desman (Galemys pyrenaicus) (Fernandes et al. 2008). Fur farms were established in many countries and harboured mink stocks from different parts of their native range. Because of the large scale and long-term nature of this farming, the number of escapees, which started to breed in the wild and became the founder individuals of feral populations, was very high (Bonesi and Palazón 2007). In Spain, mink farming started at the end of the 1950s and the number of farms reached a peak in the 1980s with about 400 farms concentrated mainly in the North West (Galicia) (Ruiz-Olmo et al. 1997). Today, feral mink populations are widely distributed across almost all of the north and centre of the Iberian Peninsula. During the last few decades, these populations experienced a rapid expansion and increased the number of nuclei in almost every 

considerably reduced at the end of the 1980s, mink escapes from the last active farms are still ongoing

79 (Bonesi and Palazón 2007).

In Europe, there is genetic information on feral American mink populations from several countries. Previous studies in Spain using microsatellite data determined that American mink populations from disjunct geographical areas appeared differentiated and not yet connected by gene flow (Lecis et al. 2008). In Scotland, Zalewski et al. (2009) and Fraser et al. (2013) found that landscape features restricted gene flow within this species. Other studies in Poland found that multiple introductions determine the genetic structure of American mink populations (Zalewski et al. 2010) and that these populations exhibit high mitochondrial genetic diversity (Zalewski et al. 2011). A study in France using microsatellite data suggested recent admixture between populations that had recently encountered each other (Bifolchi et al. 2010). Similarly, in Sweden it was found, also using microsatellite data, that genetic diversity decreased over six consecutive years of mink culling as part of a population control programme (Zalewski et al. 2016).

Despite the importance of understanding the genetic diversity within the native populations for investigating the evolutionary dynamics of invasions, no phylogeographic study has been performed so far in the North American native range of the American mink. Therefore, many genetic studies performed thus far are difficult to interpret. We used mitochondrial DNA (mtDNA) sequence data from populations in the native range to elucidate whether invasive populations in the Iberian Peninsula have single or multiple origins from the North American sources. We aimed to determine the phylogeographic structure of native and invasive populations, and to evaluate whether mitochondrial genetic diversity observed in established invasive populations can be explained by genetic characteristics of native populations. We examined whether the genetic variability of the Iberian population represented only a small part of that in its native range, as expected for many invasive species or, due to the introduction history and particular origin of these populations, this genetic variability was larger. Overall, the study aims to provide recommendations for mink control in the Iberian Peninsula with respect to determining key control areas.

\section{Materials and methods}

107

\subsection{Sample collection}

109

We used hair and tissue samples from invasive populations provided by different Autonomous

111 Communities of Spain. These samples were collected during population control operations conducted by

112 the local administrations between 2007 and 2016 as part of eradication programs and were conserved in

113 tubes containing absolute ethanol (ESM Appendix: Table S1). A total of 105 samples from Catalonia

114 (16), La Rioja (15), Galicia (12), Basque Country (20), Navarra (11), Castellon (7) and Castilla-Leon (24) 115 were included in the study. 

obtained from different biological collections: University of Alaska Museum (12), Museum of Southwester Biology (5) and Cornell University Museum of Vertebrates (4).

\subsection{DNA extraction, PCR and sequencing of mitochondrial DNA}

We extracted DNA using the QIAGEN DNeasy Blood and Tissue Kit, following the manufacturer's instructions, in a final elution volume of $100 \mu$. These extractions were carried out in a separated UVirradiated area with dedicated equipment. Samples were incubated in a lysis buffer with proteinase $\mathrm{K}$ at $56^{\circ} \mathrm{C}$ overnight to ensure maximum tissue lysis. control region (D-loop). For this purpose, we designed novel primers using complete mitochondrial sequences of several mustelids: Neovison_tRNA_pro (5'-ATC AGC ACC CAA AGC TGA CAT TCT A-3') and Neovison_Dloop_556r (5'-TGT GTA TGT CCT GTG ACC ATT GAC T-3'). PCR reactions were set up in a dedicated PCR clean room that is physically separated from post-PCR working areas and regularly decontaminated by UV-irradiation. PCR reactions were performed in a final volume of $25 \mu \mathrm{l}$, containing 2-4 $\mu$ l of genomic DNA, $1 \mu \mathrm{M}$ of each primer, $0.2 \mathrm{mM}$ dNTPs, 0.75 units of Promega GoTaq DNA polymerase and $17.5 \mu \mathrm{M}$ of bovine serum albumin under the following conditions: an initial denaturation of $2 \mathrm{~min}$ at $95^{\circ} \mathrm{C}$, followed by 35 cycles of denaturation $\left(30 \mathrm{~s}\right.$ at $\left.95^{\circ} \mathrm{C}\right)$, annealing $(30 \mathrm{~s}$ at $\left.54^{\circ} \mathrm{C}\right)$ and extension $\left(30 \mathrm{~s}\right.$ at $\left.72^{\circ} \mathrm{C}\right)$. PCR products were visualised by electrophoresis in a $1 \%$ agarose SYBR-Safe (Invitrogen) stained gel.

PCR products were purified using ExoSAP-It (Affymetrix), and both strands were sequenced using the original PCR primers at Macrogen Europe (Amsterdam, The Netherlands). Sequences were inspected, trimmed and assembled using Geneious Pro (Biomatters Ltd.). All sequences obtained in this study were deposited in European Nucleotide Archive/GenBank under accession numbers LT854061-LT854186.

\subsection{Phylogenetic and genetic diversity analyses}

Consensus sequences were aligned using MAFFT version 7.130 (Katoh et al. 2002) with default settings. Due to the presence of several gaps and ambiguous positions in a very specific region of the alignment, we manually removed positions 92 to 110 , thus leaving 554 bp in the alignment. using a general time reversible substitution model and rate heterogeneity modelled with a gamma distribution plus a proportion of invariable sites, as recommended by the program. From this tree, a haplotype genealogy was generated using Haploviewer 1.0 (Salzburger et al. 2011). 
157 Genetics Analysis System, Paradis 2010). To analyse the variation in nucleotide diversity across the

158 Iberian Peninsula, we used a visualization method that does not require the pre-definition of populations.

159 The nucleotide diversity was estimated at each sampling location by using all samples present within 30

$160 \mathrm{~km}$ of the location. This allowed the estimation of genetic diversity from a sufficient number of samples

161 at each point, yet the resolution was sufficient to distinguish regional differences in genetic diversity.

162 QGIS (http://qgis.osgeo.org) was used to plot the nucleotide diversity in the map. In the case of the North

163 American native range, it was not possible to apply this analysis due to the limited number of samples.

164 Therefore, we selected three areas with a sufficient number of samples: North West (British Columbia,

165 six samples), South East (Texas, three samples) and East (New York, four samples), in order to estimate

166 the nucleotide diversity in these specific areas.

167

168 3. Results

169

$170 \quad 3.1$ Mitochondrial phylogeographic analysis

171

172

173

A total of 16 different haplotypes of the mitochondrial control region were detected in 126 American

174 S1). The maximum likelihood phylogenetic tree showed two large clades found throughout western and

175 eastern North America, respectively (Fig. 1). The haplotype genealogy reconstructed from the maximum

176 likelihood tree revealed the same two large groups (Fig. 2a). As indicated in this genealogy, two

177 mutations unambiguously differentiate both clades. The map of samples clearly shows the geographical

178 separation of the two clades in North America (Fig. 2b). In the Iberian Peninsula, we found more samples

179 belonging to the western than to the eastern clade of North America (68 vs. 37 samples, respectively).

180 However, samples belonging to both clades were detected together in four regions of the north central

181 area of the Iberian Peninsula: Basque Country, La Rioja, Navarra and Avila (South of Castilla-Leon) (Fig. 182 2c).

183

184 ranges. While there was evidence of a geographical pattern for the individuals collected from the native range, with individual haplotypes concentrated in a single locality or close localities (Fig. 1), many haplotypes were widely dispersed in the Iberian Peninsula (Fig. 1, Fig. S1), showing that haplotypes are not informative with regards to the geographical origin of any sample.

The global genetic diversity of the American mink estimated with the control region was relatively

194 for North America and the Iberian Peninsula was $0.78 \%$ and $0.64 \%$, respectively (haplotype diversity was $1950.81,0.92$ and 0.76, respectively). However, the nucleotide diversity varied considerably when different 196 localities and populations were considered separately. Among the three areas of the native range in which 
$\pi$ was calculated separately, the population of British Columbia showed the highest nucleotide diversity

$198(0.53 \%)$ whereas New York $(0.12 \%)$ and Texas $(0 \%)$ registered lower values. In agreement with the

199 spatial mixing of clades in the central areas of the Iberian Peninsula, the map derived from the genetic

200 diversity values of the samples around each locality clearly showed maximum levels of genetic diversity

201 in these regions (Fig. 3). When values of several sampling localities were averaged, the Basque

202 population concentrated the highest nucleotide diversity $(0.61 \%)$, followed by Avila $(0.50 \%)$ and La

203 Rioja (0.25\%). From these areas, genetic diversity decreased towards the remainder of the mink

204 distribution, reaching values of $0 \%$ in some areas.

205

206

\section{Discussion}

207

Our results show that the establishment of the invasive American mink population in the Iberian Peninsula is the product of the introduction of individuals from the two main genetic lineages found in western and eastern North America. In the invasive range, these lineages registered a complete lack of phylogeographic structure. This was probably the result of the additive effect of multiple continuous

212 introductions, and the rapid expansion and encounters of the introduced populations. Overall, genetic

213 diversity was lower in the introduced than in the native populations, although in some introduced

214 populations diversity was higher to any one native population, at least with respect to the reduced native

215 area analysed so far. These results provide evidence for the potential of introduced populations to

216 maintain or increase the genetic diversity.

\section{$218 \quad 4.1$ Phylogeographic patterns}

Phylogenetic analysis revealed two large native phylogeographic lineages, which indicated a clear 221 separation between the western and eastern populations in North America. Therefore, the relationship 222 between the mtDNA haplotypes and the location from which they were sampled provides evidence of 223 phylogeographic structure among populations of American mink in their native range. Unfortunately, the 224 lack of information about sequence data of mtDNA of the American mink in North America did not allow 225 our results to be compared with those of similar studies. Other studies of plant and animal species from

226 North America have illustrated a complex phylogeographic history of the biota of this region (Shafer et 227 al. 2010; Soltis et al. 2006). The data currently available suggest that vicariance, dispersal and the 228 existence of refugia have worked in concert to produce the species' distribution and genetic divergence 229 patterns of the region (Brunsfeld et al. 2001). Future research focused on filling the gaps by sampling at 230 locations between the two clades seen in this work is required to achieve a deeper understanding of the 231 evolutionary history of the American mink in its native range.

The pattern of spatial structure recorded in North America allowed for a more precise identification of 234 the origin of invasive populations in the Iberian Peninsula. Our analysis revealed that there were 235 introductions from both western and eastern regions in North America. Additionally, the distribution of 236 the invasive haplotypes in the Iberian Peninsula suggests that at least the north central area of the Iberian 
238 introductions from both regions of North America, while the western and eastern Iberian populations

239 (Galicia, Catalonia and Castellon) originated from introductions from western North America, contrary to

240 what was previously believed (Palazón et al. 1997). This situation most likely occurred as a result of the

241 multiple origins of mink from different farms and the fast range expansion of the occupied area since

242 their introduction in the 1960s-1970s. It is also likely that farms received founder individuals from

243 different source populations in the native range.

The occurrence of the two main mitochondrial lineages in the north central area of the Iberian Peninsula suggests that the intermixing of individuals of both lineages may potentially take place.

247 However, it will be necessary to perform analysis with multiple genomic markers in the future to

248 determine whether individuals belonging to these two lineages effectively interbreed and, if so, to

249 estimate admixture levels in these populations (Pritchard et al. 2000). It is also important to note that, due

250 to the limited information derived from the mitochondrial DNA, which only reflects the maternal lineage,

251 the existence of some admixture levels in other Iberian populations cannot be discarded until genomic

252 analyses are performed. In fact, a previous study in the Iberian Peninsula based on microsatellites showed

253 that the highest admixture levels between populations were found in the Basque Country population,

254 which in principle is consistent with our results (Lecis et al. 2008). However, since no native specimens

255 were available in that study, it was not possible to determine how the identified populations were related

256 to the source populations. This confirms that it is crucial to obtain samples from the native range to shed

257 light on the relationship between invasive and native populations and to identify potential source

258 populations.

\section{$260 \quad 4.2$ Genetic diversity in the native versus invasive range}

Based on mitochondrial DNA control region sequence data, our results provide evidence that the 263 introduced American mink populations in the Iberian Peninsula have overall less genetic diversity than 264 native mink populations in North America. These results are in agreement a priori with the "genetic 265 paradox" (Allendorf and Lundquist 2003; Estoup et al. 2016), which predicts that low genetic variability 266 can be expected in invasive species because of the loss of rare alleles, as a result of the founder effect and 267 population bottlenecks (Allendorf and Lundquist 2003; Grapputo et al. 2005). Nevertheless, when

268 analysed at the population level within each range, nucleotide diversity in the population of the Basque

269 Country and La Rioja in the Iberian Peninsula was found to be greater than that recorded for North

270 American populations. The pattern registered here is consistent with other studies (e.g. Edelaar et al.

271 2015; Genton et al. 2005; Roman and Darling 2007), providing another example of an invasive species

272 retaining genetic diversity. Similarly, previous studies have demonstrated that the genetic diversity of

273 invasive populations in their new range may be increased through the admixture of lineages from multiple

274 native populations (Keller and Taylor 2010; Kolbe et al. 2008). As already indicated, the pattern observed 275 in the Iberian Peninsula could be the result of multiple introductions of mink deriving from different local 276 lineages of North America, their rapid expansion, and the encounter of lineages in the north central area 
of the Iberian Peninsula that may potentially hybridise. However, we cannot discard that cross-breeding of the different North American subspecies or populations took place within farms (Belliveau et al. 1999;

279 Dunstone 1993).

High values of genetic diversity have also been registered in some mink population of Poland

282 (Zalewski et al. 2011). In this case, mean $\pi$ for all feral mink analysed was $0.94 \%$, with values for

283 different populations ranging between 0 and $1.41 \%$. Although the mitochondrial control region fragment

284 used in that work was different to ours and a direct comparison cannot be performed, the values found in

285 some populations in Poland were much higher than in others. It is therefore likely that the same processes

286 suggested for the Iberian Peninsula (i.e. multiple introductions, rapid expansion and encounters of

287 individuals of different lineages) can be applied to other areas with invasive populations of American

288 mink

\subsection{Implications for management}

This study provides an understanding of the genetic structure and diversity of the populations of the

293 American mink in the Iberian Peninsula, which can be used to identify key control areas. Thus, one way

294 to improve the effectiveness of management programmes of an invasive species such as the American

295 mink is by incorporating molecular-based information into these programs (Hampton et al. 2004). In this

296 regard, the current spatial mixing of individuals from two different native lineages in the north central

297 area of the Iberian Peninsula (Basque Country, La Rioja, Navarra and Avila populations) and the

298 potential interbreeding between such lineages that may take place could translate, among other outcomes,

299 into a higher fitness in these individuals (e.g. Vandewoestijne et al. 2008). In fact, previous studies have

300 found a positive correlation between genetic diversity and colonization success as measured by the

301 reproduction rate (e.g. Crawford and Whitney 2010). Interestingly, Melero et al. (2012b) found that mink

302 of the Basque Country were bigger in size than mink of the rest of the Iberian Peninsula. According to

303 Melero et al. (2012b), this phenotypic variation could be due to a mixing of individuals from different

304 origins, among other possibilities. If the link between spatial mixing of mitochondrial lineages, genome

305 admixture and higher fitness is demonstrated for some populations, then higher efforts to control and

306 eradicate the American mink should be undertaken in such populations in order to impede or minimise

307 their expansion.

Current controls of the American mink in the Iberian Peninsula focus on reducing their effects on ecosystems and biodiversity (i.e., areas with local populations of threatened species, wetlands where they

311 can cause high mortalities in waterfowl and protected natural areas, etc.). In this regard, it is important to consider that the areas of the Iberian Peninsula with presence of both American mink lineages coincide with critical areas for the conservation of two of the most threatened mammals of the Iberian Peninsula,

314 the European mink and the Pyrenean desman. The American mink compete successfully for habitat and 315 prey with the European mink (Sidorovich et al. 1999; Sidorovich and MacDonald 2001), whose

316 population of the North of Spain and South West of France is highly isolated from the rest of the 
317 distribution (Michaux et al. 2005). On the other hand, the populations of Pyrenean desman of the Central

318 System have experienced a strong reduction in the last few years and are threatened with extinction.

319 Although the reasons for this decline are not well known, predation by the American mink may have

320 contributed to it (Fernandes et al. 2008). Thus, the presence of the two native lineages of the American

321 mink in the areas with these threatened species should be taken into account in future conservation plans

322 due the putative higher expansive potential of the American mink in them.

323

324 The results of this work are in line with previous studies suggesting that mink control should also be

325 directed to minimise the contact between genetically differentiated populations (Bifolchi et al. 2010;

326 Fraser et al. 2013; Lecis et al. 2008; Robertson and Gemmell 2004), and so counteract a possible increase

327 in mink fecundity and dispersal (Melero et al. 2015; Oliver et al. 2016). The present study has shown how

328 molecular-based information obtained from the invasive range, together with that from the native range,

329 was critical to characterise the sources from which the Iberian populations of the American mink

330 originated. Further studies are now necessary to obtain more detailed information, particularly in areas

331 where admixture of lineages may potentially occur, to help prioritise efforts to control and manage this

332 invasive species.

333

334

\section{Acknowledgements}

335

336

337

This work was financially supported by the research Project CGL2014-53968-P of the "Plan Nacional I+D+I del Ministerio de Economía y Competitividad" (Spain) to J.C., cofinanced with FEDER funds. K.G. was funded by a "Becas Chile-CONICYT" PhD studentship. We acknowledge the following institutions and administrations for samples: University of Alaska Museum (Mammal Collection), Museum of Southwestern Biology (Division of Mammals), Cornell University Museum of Vertebrates (Mammal Collection), Generalitat de Catalunya, Gobierno de La Rioja, Junta de Castilla y León, Xunta de Galicia (Dirección Xeral de Conservación da Natureza), Generalitat Valenciana (Centro de Recuperación de Fauna La Granja de El Saler) and Gobierno de Navarra. We wish to thank to all technicians of administrations involved in sample collection and management, in particular: Asun Gómez, Rafael Romero, Juan del Nido, Olga Alarcia, Gabriel de Pedro and Iñigo Zuberogoitia, Gloria Giralda and José María Gil. We also thank Oliver Hawlitschek and Marina Querejeta for helpful comments on the manuscript.

\section{References}

Allendorf FW, Lundquist LL (2003) Population Biology, Evolution, and Control of Invasive Species. Conserv Biol 17:24-30. doi: 10.1046/j.1523-1739.2003.02365.x

Belliveau AM, Farid A, O'Connell M, Wright JM (1999) Assessment of genetic variability in captive and wild American mink (Mustela vison) using microsatellite markers. Can J Anim Sci 79:7-16. doi: 10.4141/A97-115

356 Bifolchi A, Picard D, Lemaire C, Cormier JP, Pagano A (2010) Evidence of admixture between 

10.1007/s10592-008-9780-1

Blackburn TM, Cassey P, Lockwood JL (2009) The role of species traits in the establishment success of exotic birds. Glob Chang Biol 15:2852-2860. doi: 10.1111/j.1365-2486.2008.01841.x

Bonesi L, Chanin P, Macdonald D (2004) Competition between Eurasian otter Lutra lutra and American mink Mustela vison probed by niche shift. Oikos 106:19-26. doi: 10.1111/j.00301299.2004.12763.x

Bonesi L, Palazón S (2007) The American mink in Europe: Status, impacts, and control. Biol Conserv 134:470-483. doi: 10.1016/j.biocon.2006.09.006

Brunsfeld SJ, Sullivan J, Soltis DE, Soltis PS (2001) Comparative phylogeography of north- western North America: a synthesis. In: in J. Silvertown and J. Antonovics [Eds.], Integrating ecology and evolution in a spatial context, Blackwell Science, Oxford, UK. pp 319 - 339

Dunstone N (1993). The Mink. T\&AD Poyser Ltd., London

Edelaar P, Roques S, Hobson EA, Gonçalves Da Silva A, Avery ML, Russello MA, Senar JC, Wright TF, Carrete M, Tella JL (2015) Shared genetic diversity across the global invasive range of the monk parakeet suggests a common restricted geographic origin and the possibility of convergent selection. Mol Ecol 24:2164-2176. doi: 10.1111/mec.13157

Estoup A, Ravign V, Hufbauer R, Vitalis R, Gautier M, Facon B (2016) Is There A Genetic Paradox of Biological Invasion? Annu Rev Ecol Evol Syst 47:51-72. doi: 10.1146/annurev-ecolsys-121415

Fernandes M, Herrero J, Aulagnier S, Amori G (2008) Galemys pyrenaicus. The IUCN Red List of Threatened Species: e.T8826A12934876. http://dx.doi.org/10.2305/IUCN.UK.2008.RLTS.T8826A12934876.en

Fraser EJ, Macdonald DW, Oliver MK, Piertney S, Lambin X (2013) Using population genetic structure of an invasive mammal to target control efforts - An example of the American mink in Scotland. Biol Conserv 167:35-42. doi: 10.1016/j.biocon.2013.07.011

Genton BJ, Shykoff JA, Giraud T (2005) High genetic diversity in French invasive populations of common ragweed, Ambrosia artemisiifolia, as a result of multiple sources of introduction. Mol Ecol 14:4275-4285. doi: 10.1111/j.1365-294X.2005.02750.x

Grapputo A, Boman S, Lindström L, Lyytinen A, Mappes J (2005) The voyage of an invasive species across continents: Genetic diversity of North American and European Colorado potato beetle populations. Mol Ecol 14:4207-4219. doi: 10.1111/j.1365-294X.2005.02740.x 
Molecular techniques, wildlife management and the importance of genetic population structure and dispersal: a case study with feral pigs. J Appl Ecol 41:735-743. doi: 10.1111/j.00218901.2004.00936.x

Harrington LA, Harrington AL, Moorhouse T, Gelling M, Bonesi L, Macdonald DW (2009) American

401

402

403

404

405

406

407

408

409

410

411

412

413

414

415

416

417

418

419

420

421

422

423

424

425

426

427

428

429

430

431

432

433

434

435

436 mink control on inland rivers in southern England: An experimental test of a model strategy. Biol Conserv 142:839-849. doi: 10.1016/j.biocon.2008.12.012

Katoh K, Misawa K, Kuma K, Miyata T (2002) MAFFT: a novel method for rapid multiple sequence alignment based on fast Fourier transform. Nucleic Acids Res 30:3059-3066. doi: 10.1093/nar/gkf436

Keller SR, Taylor DR (2010) Genomic admixture increases fitness during a biological invasion. J Evol Biol 23:1720-1731. doi: 10.1111/j.1420-9101.2010.02037.x

Kolbe JJ, Glor RE, Rodríguez Schettino L, Lara AC, Larson A, Losos JB (2004) Genetic variation increases during biological invasion by a Cuban lizard. Nature 431:177-181. doi: 10.1038 /nature02807

Kolbe JJJ, Larson A, Losos JBB, de Queiroz K (2008) Admixture determines genetic diversity and population differentiation in the biological invasion of a lizard species. Biol Lett 4:434-437. doi: 10.1098/rsbl.2008.0205

Lecis R, Ferrando A, Ruiz-Olmo J, Mañas S, Domingo-Roura X (2008) Population genetic structure and distribution of introduced American mink (Mustela vison) in Spain, based on microsatellite variation. Conserv Genet 9:1149-1161. doi: 10.1007/s10592-007-9428-6

Macdonald DW, Harrington LA (2003) The American mink: The triumph and tragedy of adaptation out of context. N.Z. J. Zool. 30(4):421-441.doi: http://dx.doi.org/10.1080/03014223.2003.9518350

Maran T, Skumatov D, Gomez A, Põdra M, Abramov AV, Dinets V (2016) Mustela lutreola. The IUCN Red List of Threatened Species 2016: e.T14018A45199861.

http://dx.doi.org/10.2305/IUCN.UK.2016-1.RLTS.T14018A45199861.en

Melero Y, Plaza M, Santulli G, Saavedra D, Gosàlbez J, Ruiz-Olmo J, Palazón S (2012a) Evaluating the effect of American mink, an alien invasive species, on the abundance of a native community: is coexistence possible? Biodivers Conserv 21:1795-1809. doi: 10.1007/s10531-012-0277-3

Melero Y, Santulli G, Gómez A, Gosàlbez J, Rodriguez-Refojos C, Palazón S (2012b) Morphological variation of introduced species: The case of American mink (Neovison vison) in Spain. Mamm Biol 77:345-350. doi: 10.1016/j.mambio.2012.02.001

Melero Y, Robinson E, Lambin X (2015) Density- and age-dependent reproduction partially compensates culling efforts of invasive non-native American mink. Biol Invasions 17(9): 2645-2657. doi: $10.1007 / \mathrm{s} 10530-015-0902-7$

Michaux JR, Hardy OJ, Justy F, Fournier P, Kranz A, Cabria M, Davison A, Rosoux R, Libois R (2005) Conservation genetics and population history of the threatened European mink Mustela lutreola, with an emphasis on the west European population. Mol Ecol 14:2373-2388. doi: 10.1111/j.1365294X.2005.02597.x

Novak S, Mack R (1993) Genetic variation in Bromus tectorum (Poaceae): comparison between native and introduced populations. Heredity (Edinb) 71:167-176. doi: 10.1038/hdy.1993.121 
Oliver MK, Piertney SB, Zalewski A, Melero Y, Lambin X (2016) The compensatory potential of increased immigration following intensive American mink population control is diluted by malebiased dispersal. Biol Invasions 18:3047-3061. doi: 10.1007/s10530-016-1199-x

Palazón S, Ruiz-Olmo J, Bueno F, Bueno F, Jordan G, Palomero G, Palomero G, Munilla I, Romero R, Gimenez YJ (1997) El visón americano en España. In: El visón europeo y el visón americano en España. (Eds.) Palazón, S. and Ruiz-Olmo, J. Colección Técnica, Ministerio de Medio Ambiente. Madrid. pp 107-114

Paradis E (2010) PEGAS: An R package for population genetics with an integrated-modular approach. Bioinformatics 26:419-420. doi: 10.1093/bioinformatics/btp696

Pritchard JK, Stephens M, Donnelly P (2000) Inference of population structure using multilocus genotype data. Genetics 155:945-959. doi: 10.1111/j.1471-8286.2007.01758.x

Reid F, Schiaffini M, Schipper J (2016) Neovison vison. The IUCN Red List of Threatened Species 2016: e.T41661A45214988. http://dx.doi.org/10.2305/IUCN.UK.2016-1.RLTS.T41661A45214988.en.

Robertson BC, Gemmell NJ (2004) Defining eradication units to control invasive pests. J Appl Ecol 41:1042-1048. doi: 10.1111/j.0021-8901.2004.00984.x

Roman J, Darling JA (2007) Paradox lost: genetic diversity and the success of aquatic invasions. Trends Ecol Evol 22:454-464. doi: 10.1016/j.tree.2007.07.002

Ruiz-Olmo J, Munilla I, Romero R (1997) Distribution, Status and Colonization of the American Mink Mustela vison in Spain. J Wildl Res 2:30-36.

Salzburger W, Ewing GB, Von Haeseler A (2011) The performance of phylogenetic algorithms in estimating haplotype genealogies with migration. Mol Ecol 20:1952-1963. doi: 10.1111/j.1365294X.2011.05066.X

Santulli G (2014) Occupancy, abundance, potential distribucion and spatial competition of the critically endangered european mink (Mustela lutreola) and the invasive non-native american mink (Neovison vison) in the Iberian Peninsula. Dissertation, Universitat de Barcelona.

Shafer ABA, Cullingham CI, Côté SD, Coltman DW (2010) Of glaciers and refugia: a decade of study sheds new light on the phylogeography of northwestern North America. Mol Ecol 19:4589-4621. doi: 10.1111/j.1365-294X.2010.04828.x

Sidorovich V, Kruuk H, Macdonald D (1999) Body size, and interactions between European and American mink (Mustela lutreola and M. vison) in Eastern Europe. J Zool 248:521-527. doi: 10.1111/j.1469-7998.1999.tb01051.x

Sidorovich V, MacDonald DW (2001) Density dynamics and changes in habitat use by the European mink and other mustelids in connection with the American mink expansion in Belarus. Netherlands J Zool 51:107-126. doi: 10.1163/156854201750210878

Sol D, Maspons J, Vall-Llosera M, Bartomeus I, García-Peña GE, Piñol J, Freckleton RP (2012) Unraveling the life history of successful invaders. Science 337:580-583. doi: $10.1126 /$ science. 1221523

Soltis DE, Morris AB, McLachlan JS, Manos PS, Soltis PS (2006) Comparative phylogeography of unglaciated eastern North America. Mol Ecol 15(14):4261-4293. doi:10.1111/j.1365294X.2006.03061.x 
477

478

479

480

481

482

483

484

485

486

487

488

489

490

491

492

493

494

495

496

497

498

499

500

501

502

503

504

505

506

507

508

Stamatakis A (2014) RAxML version 8: A tool for phylogenetic analysis and post-analysis of large phylogenies. Bioinformatics 30:1312-1313. doi: 10.1093/bioinformatics/btu033

Suarez A V., Tsutsui ND (2008) The evolutionary consequences of biological invasions. Mol Ecol 17:351-360. doi: 10.1111/j.1365-294X.2007.03456.x

Uller T, Leimu R (2011) Founder events predict changes in genetic diversity during human-mediated range expansions. Glob Chang Biol 17:3478-3485. doi: 10.1111/j.1365-2486.2011.02509.x

Vandewoestijne S, Schtickzelle N, Baguette M (2008) Positive correlation between genetic diversity and fitness in a large, well-connected metapopulation. BMC Biol 6:46-55. doi: 10.1186/1741-7007-646

Zalewski A, Piertney SB, Zalewska H, Lambin X (2009) Landscape barriers reduce gene flow in an invasive carnivore: geographical and local genetic structure of American mink in Scotland. Mol Ecol 18:1601-1615. doi: 10.1111/j.1365-294X.2009.04131.x

Zalewski A, Michalska-Parda A, Bartoszewicz M, Kozakiewicz M, Brzeziński M (2010) Multiple introductions determine the genetic structure of an invasive species population: American mink Neovison vison in Poland. Biol Conserv 143:1355-1363. doi: 10.1016/j.biocon.2010.03.009

Zalewski A, Michalska-Parda A, Ratkiewicz M, Kozakiewicz M, Bartoszewicz M, Brzeziński M (2011) High mitochondrial DNA diversity of an introduced alien carnivore: Comparison of feral and ranch American mink Neovison vison in Poland. Divers Distrib 17:757-768. doi: 10.1111/j.14724642.2011.00767.x

Zalewski A, Zalewska H, Lunneryd SG, André C, Mikusiński G (2016) Reduced genetic diversity and increased structure in American mink on the Swedish coast following invasive species control. PLoS One 11(6):e0157972. doi: 10.1371/journal.pone.0157972 
509 Fig. 1 Maximum-likelihood phylogenetic tree derived from the partial mitochondrial control region 510 sequences for 126 American mink, with eastern and western clades indicated. The number of individuals

511 per locality is shown in brackets. Sequences from the native range are underlined. The scale indicates

512 number of substitutions per position.

513

514

515 Fig. 2 Phylogeographic analysis of the mitochondrial control region sequences of Neovison vison. (A)

516 Haplotype genealogy based on the maximum-likelihood tree. Circle sizes are proportional to the

517 haplotype frequency and small filled circles are inferred haplotypes not present in the sample. (B, C) Map

518 of native (B) and invasive (C) ranges showing the 126 samples of $N$. vison used in this study. Red and

519 blue colours represent the eastern and western clades, respectively. Grey areas represent the original

520 distribution of N. vison downloaded from the IUCN Red List of Threatened Species website (Reid et al.

521 2016) (B) and the occupancy area of mink in the Peninsula (MAGRAMA, 2013) (C). AL: Alaska, BC:

522 British Columbia, MT: Montana, WY: Wyoming, TX: Texas, NY: New York, GA: Galicia, CL: Castilla-

523 Leon, AV: Avila, LR: La Rioja, BC: Basque Country, NAV: Navarra, CAS: Castellon, CAT: Catalonia

524

525

526 Fig. 3 Map plotting genetic diversity $(\pi)$ in different sampling localities of Neovison vison in the Iberian

527 Peninsula. Colours of the sample points indicate the nucleotide diversity according to the provided scale.

528

529

530

531

532

533

534

535

536

537

538

539

540

541

542

543

544

545

546

547

548 
BRITISH COLUMBIA (1)

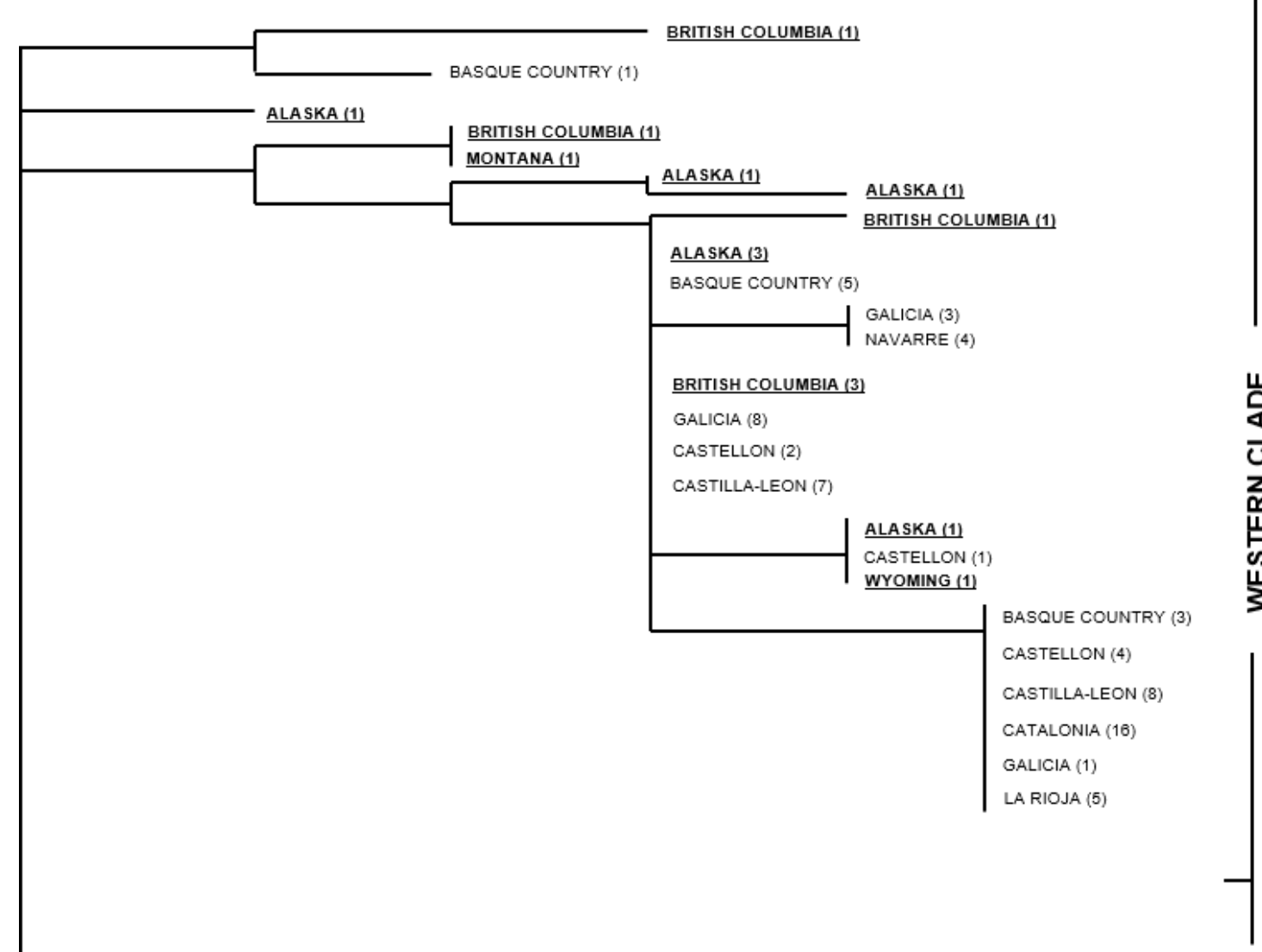

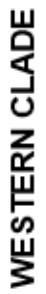

CASTELLON (4)

CASTILLA-LEON (8)

CATALONIA (16)

GALICIA (1)

ASTILLA-LEON ( $(\theta)$

NEW YORK (2

NEW YORK (2)

LA RIOJA (10)

NAVARRE (7)

TEXAS (3)

$550 \quad$ Fig. 1

551

552

553

554

555

556

557

558

559

560 


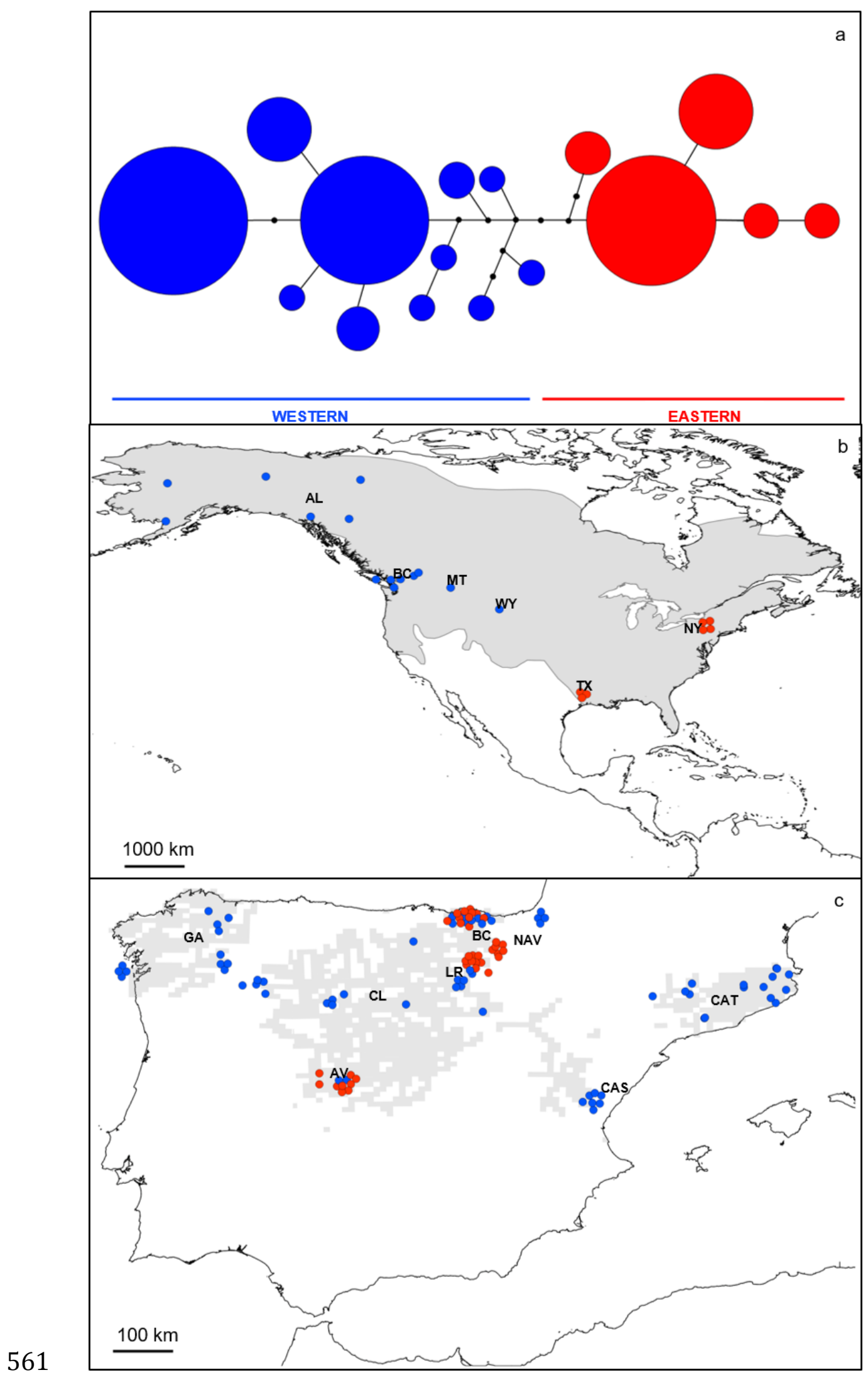

562 Fig. 2

563

564

565 


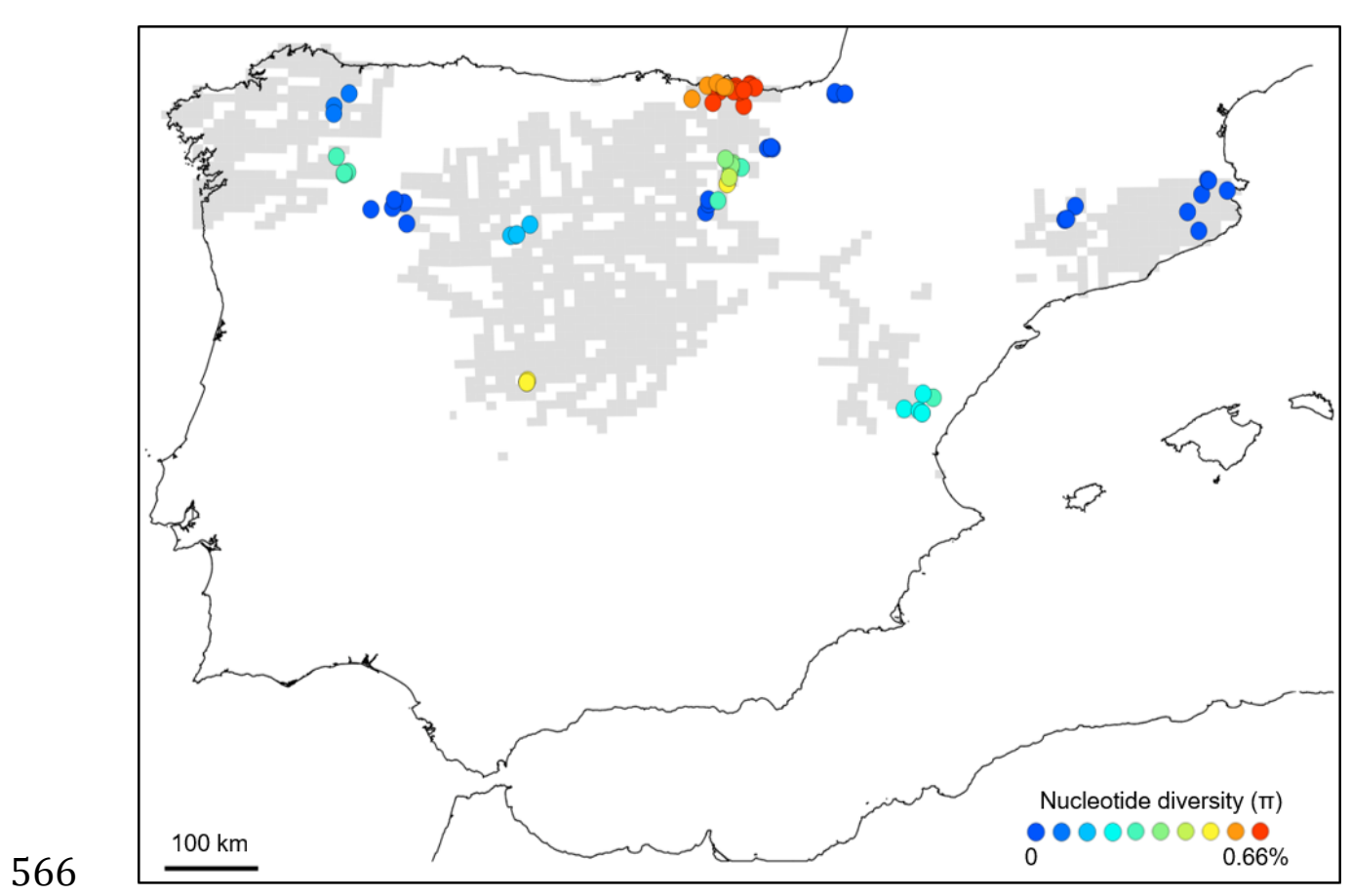

567 Fig. 3

568 